\title{
Contextual layers of service experience in professional business services
}

\begin{abstract}
Purpose: This study provides us with new knowledge in the form of conceptual framework of the contextual layers of service experience within professional business services. We aim to answer following questions: 1) What kinds of contextual layers can be identified influencing service experience? 2) How specific characteristics of professional service context may influence customer experience at these different layers?
\end{abstract}

Design/methodology/approach: The framework is based on extensive literature review considering research in the fields of service and relationship perspectives, likewise professional services.

Findings: A framework of different contextual layers of service experience is generated that is specifically adapted to the specific context of professional business services.

Originality/value: Only a limited number of studies seem to address the highly topical context of professional/knowledge-intensive business services and relationships. We tie the discussion concerning different contextual layers of service experience to this specific operating context with the aim of identifying their importance and influence in service experience. Related to this context our study highlights the importance of understanding role of individuals in service experience, rarely emphasized in B-to-B dyadic setting. The framework also contributes to current discussion regarding service experience, and 'zooms in' to the context and its detailed levels.

Keywords: Service experience, professional business service, context 


\section{Introduction}

Customer experience has been recently recognized as one of the most important current research priorities (Marketing Science Institute, 2016) and both practitioners and scholars acknowledge the close connection between customers' experiences and perceived value (e.g., Jaakkola et al., 2015; Helkkula and Kelleher, 2010; Grewal et al., 2009). Focusing on customer's service experience and its formation will aid us in creating in-depth customer understanding needed in developing new value generating services.

Professional business services are, among others, management/IT/HR/technology consulting, legal, financial, advertising, and design services (see e.g. Von Nordenflycht, 2010; Muller and Doloreux, 2009; Løvendahl et al., 2001). Being based on highly individual-embedded expertise, creativity and problem-solving skills of professionals working with the customer (Løwendahl et al., 2001; Von Nordenflycht, 2010), these services represent an interesting setting to study service experience. It is the expertise, or knowledge, of the professional that is in the central role. Consequently, the most commonly used attributes to describe professional services are the high knowledge-intensity and intangibility of the service content, the problem-solving quality and high rate of customization of the service process, and the deeply interactive and reciprocal nature of the relationship between the service provider and the client (see e.g. Aarikka-Stenroos and Jaakkola, 2012; Muller and Doloreux, 2009; Jaakkola and Halinen, 2006; Løvendahl et al., 2001). All these specific characteristics make these services also potentially challenging in the formation of superior service experience (e.g., Ojasalo, 2001).

This is also because the process, and the outcome, are not easily standardized but are often context and client dependent (Jaakkola and Halinen, 2006; Løvendahl et al., 2001). The service provider can 
utilize not only his/her knowledge-base and expertise, but must also rely on personal judgement and autonomous decision-making during the problem solving process (von Nordenflycht, 2010). Due to the fact that the service provider possesses knowledge and capabilities the client does not have, there is argued to be information asymmetry between the provider and the client, meaning that the client may find it difficult to evaluate even the outcome, not to mention the problem solving process itself (see e.g. Aarikka-Stenroos and Jaakkola, 2012; Ojasalo, 2001). Because of this asymmetry they may also lack capabilities to describe their actual needs before and during the process (ibid.). Therefore, especially professional service organizations are said to operate according to some set of professional codes of ethics, and according to different types of quality assurances (von Nordenflycht, 2010).

From above it follows, that the relationship between the service provider and the client must be reciprocal in nature, and the service process requires high levels of interaction, and customer participation (Aarikka-Stenroos and Jaakkola, 2012; Løvendahl et al., 2001). It has also been argued that mutual trust between the parties (Halinen, 1996), as well as effective dialogue and sharing of critical information (see e.g. Aarikka-Stenroos and Jaakkola, 2012; Bettencourt et al., 2002), are needed for service process to take place. Indeed, regardless of the information asymmetry, the client is a critical actor in the process as it is only through the information and knowledge the client provides that the client-specific problem solving process can succeed (ibid.). This is also highlighted, since the needs, requirements and expectations of clients can also be very complex (Hill and Johnson, 2004). Indeed, clients need service providers to conceptualize their actual needs for them. Notably, the process, and the relationship between the service provider and the client is anything but easy, and can include conflicting interests, opinions, and viewpoints (see e.g. Aarikka-Stenroos and Jaakkola, 2012). We suggest that all these specific contextual characteristics of professional business services are arguments for this field being extremely fruitful platform to study service experience and its formation. 
Especially, this specific context is justifiable because of its individual-boundness. The focus of studying business in general, and through a so called service lens in particular, is shifting to a view, which emphasizes that value is interpreted and experienced individually and subjectively by each actor (Lipkin, 2016; Jaakkola et al., 2015; Vargo and Lusch, 2011; Edvardsson et al., 2011; Frow and Payne, 2007), although there are many actors involved in the business relationship. The need to examine this phenomenon is rooted to the recognized dilemma in social sciences of moving between micro and macro levels of analysis (e.g., Sawyer, 2001; Coleman, 1984; Emirbayer and Mische, 1998). As Coleman $(1984,85)$ suggest: "The problem is this: we understand and can model the behavior at the level of individuals, but are seldom able to make an appropriate transition from there to the behavior of the system composed of those same individuals". Thus, even though the value of a service is experienced individually, this experiencing takes place in a certain operating and social context (see e.g. Vargo and Lusch, 2008 "value-in-use” or Chandler and Vargo, 2011; Edvardsson et al., 2011 "value-in-(social)-context"). The role of context is significant, for it "frames exchange, service, and the potentiality of resources from the unique perspective of each actor" (Chandler and Vargo, 2011, p. 45, see also Lipkin, 2016; Edvardsson et al., 2011; Vargo and Lusch, 2004). In other words, experience is socially constructed (Helkkula et al., 2012b), and emerge when actors interact with each other (Jaakkola et al., 2015). Hence, in analyzing and understanding service experience, it is not enough to understand resources, actors who integrate them, and the process of integration, but one should pay close attention to the context in question (Edvardsson et al., 2011; Chandler and Vargo, 2011).

Recent work e.g. by Mele et al. (2015), Wieland et al. (2016) and Leroy et al. (2013) have brought up a notion that there still are gaps in our knowledge when it comes to the influence of context to service experience. Existing discussions put emphasis especially on the characteristics and influence 
of a wider service system (e.g. Vargo et al., 2008), service ecosystem (e.g. Vargo and Lusch, 2011; Vargo et al., 2008) or the market (Mele et al., 2015). That is, instead of concentrating on the immediate context where actors operate in a specific time and place, they investigate the wider environment or a system - the "big picture" (Vargo and Lusch, 2011; Wieland et al., 2016). In line with that, Leroy et al. (2013) argue that while much attention has been recently given to investigating value and its formation by "zooming out", it would, however, be equally important to "zoom in" to find the nuances and specifics (ibid.). We agree with Leroy et al. (2013), and suggest that in business relationships there is a need to pay more attention also to the micro level including dyadic business relationships and especially individuals cooperating with the customer in order to better understand service experience. In other words, even though in the big picture, business relationships take place in a wide network of actors interacting which each other, each interaction can still be traced back to the level of a dyad. Moreover, when zooming in even more, there are individuals, who, according to service experience literature, subjectively experience the world around them (Jaakkola et al., 2015). Therefore, when discussing about service experience, that experience is not "organizational" - one cannot ignore individuals and their subjective experiences. Actually, one cannot ignore any level of analysis, for those levels influence each other and are in dynamic interaction: "Higher level regularities are often the result of quite simple rules and local interactions at the lower level" (Sawyer, 2001, 555) and vice versa: Institutional context influence actors in the context.

In this study, the operating context is professional B2B services, an important and growing field of business that involves highly interactive and interrelated relationship between service providers and customers. As mentioned, these relationships are usually based on problem-solving activities, and service providers might not even be able to offer the service without customer's intensive participation (Aarikka-Stenroos and Jaakkola, 2012). Due to the specific nature of these kinds of relationships, and difficulty in evaluating process or outcome of service because of its abstract 
components, expectations for services and service experiences play important role in them. We suggest that this specific context provides an interesting setting to study service experience and influences of different contextual levels. This is also because most of the previous studies on experience have focused on $\mathrm{B} 2 \mathrm{C}$ context, leaving room for this particular setting to give us new perspectives on the subject.

To sum up, to be able to understand the essence of service experience, this study explores it from both macro and micro perspectives to better understand the complexity of service experience formation, and provides new knowledge in the form of conceptual framework of the contextual layers of service experience within professional business services. Here we focus especially to the specific characteristics of the type of services and what kind of implications those characteristics have at different (as we call them) "layers" of service experience. The framework is based on extensive literature review considering research in the fields of service and relationship perspectives, likewise professional services. We aim to answer following questions: 1) What kinds of contextual layers can be identified influencing service experience? 2) How specific characteristics of professional service context may influence customer experience at these different layers?

We suggest that the main contribution of this paper relates to B-to-B relationship research emphasizing the importance of understanding different levels of service experience formation and interaction between those levels. We have a special emphasis on business relationships in the field of professional services, which is a less studied from the service experience perspective, although being highly individual-embedded in its service provision. In addition, we see that there is a contribution also to service research focused on service ecosystems that mainly ignore the relationship and individual level. 
This paper is organized as follows: first, we briefly present the research design of our conceptual paper. Second, current discussions and definitions related to the concept of service experience and context are introduced. After that we will present the layers of context in the formation of business service experience basing on existing research. In the end of this paper we will conclude our current findings and suggest managerial implications as well as avenues for future research.

\section{Research design}

In order to answer the research questions, we build upon the logic of a conceptual review (Kennedy, 2007; Baumeister and Leary, 1997). According to MacInnis (2011) conceptual studies can contribute to knowledge in various ways, for example by envisioning new ideas, debating ideas or explicating ideas that all move the field of marketing forward by setting an agenda for future research. In other words, integrative reviews, like our study here, contribute to the process of justification by validating what is known. The flexibility of the conceptual approach enables combining a range of source materials and concepts, and address also such issues that are more implicitly discussed in the existing research (see e.g. Kennedy, 2007).

As the purpose of this study is to create a conceptual framework on the basis of an extensive literature review, the first stage in addressing the aim was to identify and collect as many relevant research articles as possible on the topic under research. Following the study of Aarikka-Stenroos et al. (2014) we chose to employ two relevant databases rather than a set of high ranking journals to ensure rich and versatile set of articles. We selected the multidisciplinary EBSCO Business Source database and ProQuest database as they cover a wide range of high quality journals in the field of marketing. The search for materials subsequently involved keywords such as "service experience", "professional business service", "professional business relationship", and "context". In addition, we utilized a 
snowball sampling method in which primary data sources nominate another potential data sources to be used in the research (see e.g. Noy, 2008) by identifying new relevant articles from the references in the primary articles found using databases. In total, we have reviewed 71 articles that form the basis for the conceptual framework.

In analyzing the articles, we identified the empirical and conceptual findings and ideas contained in these studies that we could use to answer our research questions. We selected and combined diverse concepts and definitions from existing discussions concerning e.g. assumptions of the nature of the service experience, professional business service and context as well as the empirical findings related to these key aspects of the study. The aim was to accommodate extant knowledge, explain puzzling findings and reveal novel insights from the data (see MacInnis, 2011). Next, we will discuss what state-of-the-art literature so far tells us about service experience and related contexts and then combine perspectives and define layers of contextual setting for service experience in professional services based on our conceptual review.

\section{Service experience}

As was indicated, there is a very close connection between the concepts of value and service experience (Helkkula and Kelleher, 2010), as value is what we experience it to be (Frow and Payne, 2007; Prahalad and Ramaswamy, 2004). According to Helkkula and Kelleher (2010), (customer) perceived value and (customer's) service experience form a circular process where “customer's ongoing service experience influences customer perceived value and customer perceived value influences cumulative customer service experience" (p. 48). Hence, one can argue that service experience and value are so heavily intertwined concepts that it is difficult to fully separate them, and therefore many scholars have begun to discuss about experiential value (see e.g. Vargo and Lusch, 
2011). Ergo, even though we will mostly refer to service experience research in this study, we will also utilize phenomenological value literature, as its underlying assumptions are basically the same.

However, even though experience is regarded to be an integral element of the whole service business, the concept of service experience has been defined and dealt with in various ways depending on the theoretical background and the research context (Lipkin, 2016; Helkkula, 2011). To begin with, in service research, the terms 'customer experience' and 'service experience' have been used quite in similar ways, even as synonyms. Because customer experience refers to a narrower, more specific role of the "experiencer", i.e. that of a customer (Lipkin, 2016; Meyer and Schwager, 2007), whereas service experience refers to experience of any actor (e.g. customer, service provider, a third party) (Jaakkola et al., 2015), we will use the latter, more encompassing term in this study.

Moving on, both Helkkula (2011) and Lipkin (2016) have categorized existing service (Helkkula) and customer (Lipkin) experience conceptualizations. Lipkin has also analyzed how existing conceptualizations regard service experience to be formed. Both researchers have identified three approaches: according to Helkkula, these are process-based, outcome-based and phenomenological (see also Dube and Helkkula, 2015), and according to Lipkin, stimulus-, interaction, and sensemaking-based. First, Helkkula's category of outcome-based characterizations regard experience to be a measurable attribute or a variable of a service (see e.g. Verhoef et al., 2009, Lemke et al., 2011). A somewhat similar category is Lipkin's stimulus-based perspective, which refers to studies that regard customer experience to be individual's "subjective and internal responses to, or contacts with, service elements controlled by the service provider" (2016, p. 685). Hence, service experience forms when an individual reacts to a service in one way or another. Second, process-based characterizations defined by Helkkula acknowledge that experience is embedded in the service process. An example is Edvardsson et al. (2005, p. 151) who describe service experience as “...a service process that creates 
the customer's cognitive, emotional, and behavioral responses, resulting in a mental mark, a memory." Lipkin's interaction-based perspective relates closely to this category, as it refers to studies that deal with individual's "subjective and internal responses to, and interactions with, the service organization" (2016, p. 685). In this viewpoint, service experience is formed in a more interactive way, i.e. individual is a more active participant. Both outcome and process views have been widely acknowledged also in extant literature on value creation in B2B relationships. For example, MacDonald et al. (2011) suggest that customers evaluate both the usage processes (not only the provider's but also their own) and the service. In her study Komulainen (2014) found that in technological B2B services customer value involves both evaluation of the factors in relation to the value co-creation process between counterparts and the outcome of the service usage (see also Lapierre, 2000).

However, to create in-depth understanding of service experience in the specific context of professional business services, third category suggested by both Helkkula and Lipkin provides probably the most interesting insights. Phenomenological characterizations (Helkkula, 2011) regard individual actors to be the subject of service experience. In other words, experience is a subjective interpretation or response of an individual. Such experience can be e.g. perception, imagination, thought, emotion, desire, volition and action (Jaakkola et al., 2015; Smith, 2007). It is noteworthy that indeed, an individual's experience can also be something imagined, and include temporal elements of past, present and future (Jaakkola et al., 2015; Helkkula et al., 2012a). Yet, the phenomenological characterizations also acknowledge that individuals do not exist in isolation, but live in a social world, and therefore experience is simultaneously social and context-specific (Akaka et al., 2015; Helkkula, 2011). In a similar vein, in Lipkin's categorization phenomenological types of conceptualizations fall into sense-making-based perspective, where customer experience is studied as "a phenomenon involving subjective, active, collective and dynamic sense-making" (2016, p. 685). 
Hence, service experience is formed through "circular interpretation and sense-making, usually based on the individual's visible and invisible actions and interactions" (ibid.). Consequently, even though experience is subjective, it is heavily dependent on the context, and is formed in interaction with the context. Notably, as Lipkin (ibid.) notes, one cannot ignore either the individual or the social side of experience and its formation, and when studying service experience, there should a balance between these two. However, it is the individual who subjectively experiences the context around her/him, and therefore it is the individual who is in the key role (ibid.). This is well in line with what is presented earlier related to characteristics of professional services and therefore this category best suites to understanding service experience in professional business services.

\section{The context of service experience}

Thus far we have indicated that according to prevalent service research, service experience is very context-dependent. However, when evaluating service literature, for example S-D logic and service logic, one can notice that the definitions of context vary. Hence, what is meant by context depends significantly on who is defining it and for what purpose. Context can refer to the immediate surroundings of service experience, such as a service provider-customer relationship (e.g. Payne $e t$ al., 2008; FitzPatrick et al., 2015), a physical service encounter (e.g. Echeverri and Skålen, 2011), a specific event (e.g. Binkhorst and Den Dekker, 2009), a certain business sector or industry (Frow et al., 2016), a wider-level ecosystem or market (e.g. Vargo and Lusch, 2011), or anything in between separately or simultaneously.

On the other hand, context can also refer to more abstract concepts, such as symbol systems, social structures, culture etc. (Akaka et al., 2015), or time (Medlin, 2004). As indicated in the previous section, Helkkula et al. (2012a) argue that context is social, yet it is determined individually. This 
means that for example a service context offered or proposed by a service provider, and in which a certain service delivery may take place, may not be the same than the context through which a customer experiences value (see also Grönroos and Gummerus, 2014). However, the context is simultaneously jointly created together with the actors that operate in it (Helkkula et al., 2012a; Akaka et al., 2015).

How, then, conceptualize context of service experience in general terms? Chandler and Vargo (2011) provide a useful short definition of context when they discuss value creating service-to-service exchanges between actors. For them, context is "a unique set of actors and the unique reciprocal links among them" (p. 41). Furthermore, from the uniqueness of actors and links it follows that any given context is also unique in the sets of resources and service (Chanlder and Vargo, 2011).

This is in line with what we know of professional services, where the relationship between service provider and the client is often highly interactive and reciprocal in nature, including e.g. an extensive amount of intensive dialogue and complex information sharing (e.g. Aarikka-Stenroos and Jaakkola, 2012). Because of the high level of context-specific knowledge and unique solutions needed in service provision, relationships are often long-lasting and even personified (Ulkuniemi and Nätti, 2017)

\section{Layers of context in the formation of business service experience}

Overall, the nature of context can be characterized to be heterogeneous and distinctive: it can be anything from an actor and its connections to hundreds of actors and hundreds of links (Chandler and Vargo, 2011; Håkansson and Snehota, 1989), and hence one can identify several layers in a given context (Chandler and Vargo, 2011). As mentioned, Leroy et al. (2013) refer to 'zooming in' to and 'zooming out' of a context for value creation, and argue that from different levels one can observe 
different things. Next we will summarize what types of contextual layers this 'zooming' has in existing literature typically generated, especially from the viewpoint of service experience, and shortly illustrate the previous empirical research conducted on the different observation levels.

Notably, Leroy et al. (2013) refer to observational approach of Desjeux when they introduce the contextual layers. They argue that when zooming into a context, its lowest level of observation is biological: individual actor's brain and its activities. What happens in the brain, why and what consequences it has is the playground of neuro sciences, and will not therefore be dealt in more detail in this paper. Nevertheless, it is, of course, inevitable that what happens in the brain has a profound impact on e.g. service experience.

Individual layer. The second layer of context according to Leroy et al. (2013), and starting point of this paper, is then the individual, a single actor (human being) and her/his behavior, attitude and cognition among other (Leroy et al., 2013). From service experience point of view, this is the contextual layer that depicts how a single actor operates and perceives her/his relationships and value propositions (Leroy et al., 2013). Hence, it is the core layer of analysis, as service experience is regarded to be subjective to an individual (Jaakkola et al., 2015).

The layer of an individual was in the center of the very first consumption experience discussions (Holbrook and Hirschman, 1982), and in studies concentrating on consumer's experiences, it still is a very common analytical layer (see e.g. Dube and Helkkula, 2015; Helkkula et al., 2012a; Lemke et al., 2011). In these studies, the subject of study is hence an individual consumer, or if not the word consumer used, a customer that is an individual human being, and the context is evaluated from the individual's point of view, even though there might be also social or other networks of actors that surround the individual (see e.g. Carù and Cova, 2015). However, in discussions of a more generic 
business actor, there seems to be ambiguity in current literature in what is actually meant by the term actor (Ekman et al., 2016). For Grönroos and Gummerus (2014), an actor participating in direct or indirect interactions can be either a human actor or an intelligent system. The customer-dominant logic of service argues that customer is in the center of value creation, but defines the customer to be anything from a consumer to firms and organizations (Heinonen and Strandvik, 2015). Echeverri and Skålén (2011) discuss about practitioners or human actors involved in interaction leading to value creation or destruction. Ekman et al. (2016), who argued that the term actor is ambiguous, resulted in defining different types of actor roles, such as provider and beneficiary, in service networks. They also utilized a term generic actor suggested by e.g. Vargo and Lusch (2011), by which they mean an entity engaging in value propositions and co-creation, be it an individual, group of individuals, or a set of firms.

Based on our conceptual review there are number of empirical studies on service experiences on the individual level. However, most of these empirical studies focus on B2C context and discuss individuals as consumers. For example, in the recent study of direct and indirect use experiences of smartphone app users by Dube and Helkkula (2015) the authors concluded that the service experience of the user emerged from the combination of directly and indirectly experienced time, outcomes, location, and process. There are some studies in B2B context, such as Lemke et al. (2011) who studied if and how customers construe experience quality both in B2B and B2C contexts. They identified altogether 119 constructs to experience quality, and concluded that experiences together with relationships outcomes (e.g. commitment, purchase, retention, and word-of-mouth), usage quality, and the overall context were important elements of value-in-use. Also the study of Flint et al. (2011) is situated at this level of analysis. They report on two survey studies that link supplier's customer value anticipation capacity to customer satisfaction and loyalty. Research on service experience at the individual level in professional service setting seems to be very scarce if not nonexistent. This is 
although these services are - as mentioned - highly individual-bound and person-to-person interaction in service provision is highlighted (Nätti and Ojasalo, 2008). Likewise, creativity and customerspecific problem solving are needed. These characteristics tightly bound to individuals in the service context make this industry an interesting setting for further exploring phenomenon of service experience.

Hence, first of all, when evaluating service experience at the contextual level of an individual, one must pay attention to what is meant by an individual - and if it refers to a generic actor, whether the actor actually is single individual, or a group of individuals (e.g., organizational buying center) that are regarded to be a single entity. For example, in social science the concept of "corporate actor" is presented, emphasizing that organizations are based on a microfoundation of its individual actors (Coleman, 1984). In line with that, Emirbayer and Mische (1998) discuss the double constitution of structure and agency. Thus, from the viewpoint of phenomenological service experience, then, one must then bear in mind that even though experiences have a profound social element, they are by definition argued to be a subjective matter. This is also important to be taken into account of with regard to dyadic relationships in professional service context.

Dyadic layer. Moving on, according to Leroy et al. (2013), the third layer of context is a micro level. Micro layer is also discussed by e.g. Chandler and Vargo (2011), and in business network literature a similar concept is that of a dyad (e.g. Alajoutsijärvi et al., 1999). This layer refers to service-toservice exchanges or, in more general terms, relationships that occur directly between two individual actors (Leroy et al., 2013; Chandler and Vargo, 2011). Notably, the micro level can also refer to a scale of small groups (Leroy et al., 2013). 
According to Chandler and Vargo (2011), this layer depicts a situation where actors serve each other directly. The dyadic layer of context has been in the core of the relationship and network perspectives (Möller and Halinen, 1999; Ritter et al., 2004). In their analyses of the levels of relationship and network management both Möller and Halinen (1999) and Ritter et al. (2004), for example, regard dyads as the "basic" unit of relationship analysis. Akaka and Vargo (2015) note that other concepts that somewhat relate to dyadic level in service research are e.g. the service encounter, i.e. a dyadic interaction between a service provider and a customer, and the servicescape, i.e. physical and social spaces framing service encounters.

Empirical studies regarding service experience at dyadic context seem to be quite rare. The couple of ones we found also seem to be focused on service experience outcomes (e.g. positive or negative experiences from a service), or the effects of experiences (see e.g. Bolton et al., 2006, who investigate customer retention). Their objective seems to be more on finding ways to create positive customer experiences through managing co-creation process. For example, Ponsignon et al. (2015) identify different issues related to customer experience management, e.g. establishing stages in the customer journey lifecycle, tracking and improving under-performing moments of truth, personalizing the experience of individual customer, engaging customers in learning through education and guidance, and applying sensory design on tangible and visible interactive elements.

From the professional service perspective, Aarikka-Stenroos and Jaakkola (2012) studied value (closely related to service experience) in knowledge-intensive business services, and focused on cocreation in a dyadic relationship between customer and service provider. They found that value cocreation in the context of complex offerings occurs through a dyadic problem solving process which includes diagnosing needs, designing solutions, organizing the process, managing conflicts, and 
implementation. They also investigated the influence of roles and resources of the actors in this process.

Indeed, in professional service dyads there are many specific characteristics that can influence service encounters and experience. Because of the abstract nature of services in question (i.e. unforeseen outcome of service process), customers often aim to build close relationships with professionals they trust and, thus, relationships tend to become even personified (Ulkuniemi and Nätti, 2017; Løwendahl et al., 2001). Consequently, service experience may become very bound to the single expert, likewise expectation level for service quality. Individual-embeddedness of relationships may also generate organizational challenges for customer relationship coordination, for replacement or distribution of work (Nätti and Ojasalo, 2008; Jensen et al. 2010). For example, implementing key account system in professional service firms to enhance customer work may be challenging because of strong social bonds and "customer ownership" individual experts tend to maintain (Nätti and Palo, 2012)

To sum up, when analyzing service experience at the micro/dyadic layer of context, the subject of study is a dyad consisting of two actors. As said, this layer of context is the 'basic' unit of relationships and hence the one through which one can investigate direct interactions between actors, and consequently co-creation. As was indicated above, an actor can, however, represent either an individual, groups of individuals (also firms or organizations) - or even intellectual systems. Hence, when investigating service experience at the dyadic layer, one must be clear and precise in defining what is meant by an actor. As mentioned above, in professional service provision there are many characteristics that naturally emphasize meaning of individuals as active and subjectively experiencing actors in the dyad. Thus, even though the social aspects of an individual's service experience can be investigated at the dyadic layer of context, the subjective nature of experience should be taken into consideration also at this layer. However, to understand the service experience 
at individual and dyadic level, also understanding of wider influential environment is needed. After all, every individual and dyad are embedded to its surroundings. Understanding its meaning is fundamentally important, because through this one can acknowledge how individual operations of actors and dyads are relative to larger scale social structures, and also vice versa; they create those structures (Frow et al., 2016, see also Chandler and Vargo, 2011), although when observing the context from different levels, one just sees different aspects of the whole (Leroy et al., 2013).

Institutional environment. Dyads form networks where actors can influence each other directly or indirectly. From the dyad's point of view, the network layer depicts the wider web of relationships the actors are embedded in. Hence, identifying the existence and influence of this layer is substantial for the firms involved in professional business service relationships. There are different network layers; 1) immediate surroundings for dyadic relationship (e.g., Alajoutsijärvi et al., 1999; "focal net”), 2) more complex networks consisting of direct and also indirect relationships between several distinct actors (Chandler and Vargo, 2011; Ritter et al., 2004; Möller and Halinen, 1999) and finally, 3) even wider service ecosystems where our attention is directed to the systemic nature of service experience. Service ecosystem is a network of relationships where actors and their resources are linked through value propositions (Frow et al., 2016), and where co-creation occurs through the integration of both direct and indirect links between actors and resources that can be public, private and/or market-facing (Wieland et al., 2016). For example, Frow et al. (2016) illustrate this broader network in which a focal actor operates in. This can also refer to the scale of social categories including culture, social classes, genres and so forth (Leroy et al., 2013).

Social and cultural perspective leads us to institutional approach, which is important contextual layer of service experience. Vargo and Lusch (2016) refined their definition of a service ecosystem as being relatively self-contained, self-adjusting systems of resource-integrating actors connected by shared 
institutional arrangements and mutual value creation through service exchange. Hence, they had adopted the concepts of institutional theory in order to describe and understand co-creation in a wider context they refer to as service ecosystem. "Institutions" can be defined as humanly devised rules, norms and meanings that enable and constrain human action (Scott, 2001). Institutional arrangements, referred to also as institutional logic, are then the "interdependent assemblages of institutions" (Vargo and Lusch, 2016). Institutions represent "the more enduring features of social life" (Giddens, 1984 via Wieland et al., 2016, p. 8), or "the rules of the game in a society" (North, 1990 via Edvardsson $e t$ al., 2014, p. 295). Institutions therefore guide human interaction and provide mutual expectations regarding e.g. resource integration (Wieland et al., 2016; Edvardsson et al., 2014).

Indeed, actors surrounding individuals and dyads form institutional environment influencing service experience. And the other way around; these individuals and dyads from their part maintain and form these institutions. For example, Storbacka et al. (2016) argue that there is an interplay between layers of context, and that it takes place through three types of mechanisms: situational mechanisms (how macro-level, i.e. institutional contexts influence actors), action-formation mechanisms (how actors assimilate "the contextual conditions into action"), and transformational mechanisms (how actors' actions and interactions influence macro-level, i.e. institutional contexts) (p. 3009). Also Wieland et al. (2016) and Edvardsson et al. (2014) have conceptually investigated how institutions and institutional arrangements change over time. Wieland et al. (2016), referring to earlier work of Lawrence and Suddaby, note that actors and their (resource integrating) activities change institutions by creating, maintaining and disrupting them: the context influences its actors but also vice versa. Edvardsson et al. (2014) investigated institutions from the viewpoint of three "institutional pillars": regulative (all formal rules), normative (norms and values), and cognitive (perceptions of reality). They argue that regulative, normative and cognitive institutions guide actors' usage of resources and coordination of resource integration in several ways. 
As noted previously, the phenomenological or sense-making approach is the one we argue to be of specific interest in professional business service context. Lipkin (2016) states that it is the more holistic collective sense-making perspective that succeeds best "in mirroring today's service settings" (p. 694) that are characterized by things such as technological change (e.g. the emergence of social media), increased competition, urbanization, and active, knowledgeable actors - topics that characterize current professional service business field as well, and strengthen the meaning of collective sense making and institutions in this otherwise highly individualistic and professionalbound environment. Collective sense-making is not a new thing related to research in professional services. For example Empson (2001) suggest that similarity of knowledge bases between individuals and companies makes knowledge transfer (i.e. also sense-making) easier. In line with that, discussion around communities of practice, "groups of people informally bound together by shared expertise and passion" (Wenger and Snyder, 2000: 139), emphasize the importance of shared professionalism and collective sense-making. Sense-making happens in the professional groups with similar mindsets and this sense-making is influenced by, but also building up professional institutions including social norms, regulations and basic assumptions that affect every group member's perceptions. These professional institutions can also cause certain context-specific behavior patterns for service provision, not necessarily understood by other professionals. Institutions influence both service providers and customers, forming expectations and experiences. However, although professional institutions are powerful, at the individual level institutions can also vary based on individual's social links, personal history, capabilities and resources, for example.

What is also remarkable from the institutional layer point of view is professional codes or ethical instructions professional service providers follow that can form influential institutions, i.e. frameworks for expectations and experiences built around service generation. These are only some 
examples of complex contextual and social conditions in professional service environment. We therefore argue that in line with the work conducted in phenomenological/sense-making studies, by emphasizing both the individual experience and the overall context influencing it, one can create a comprehensive and contemporary view of service experience within professional services.

\section{Conclusions}

Based on our conceptual review, varying amount of empirical research exists of service experience at different contextual layers. For example, at the individual level there are a plenty of B2C studies but on the other layers the research has been mainly theoretical in nature without connection to certain empirical context. Specifically, very rare studies seem to address the highly topical context of professional business services and relationships. We tied the discussion concerning different contextual layers to this specific operating context to be able to approach service experience by exploring actual business relationships and this way to create a broader understanding of the importance and influence of the different contextual layers from the empirical and more concrete perspective in certain operating context.

This paper has explored how the existing literature has defined service experience and the context surrounding it. It has also presented some of the empirical work already conducted on this field. However, in relation to this, our conceptual study reveals that more empirical research specifically in B2B context and on different layers is needed to create more comprehensive understanding of the service experience and related value.

Based on this study, a conceptual framework is suggested that combines the contextual layers influencing service experience (see table 1). The framework clarifies the context in which a dyadic 
relationship is embedded and emphasizes the important role of an individual. Consequently, the framework contributes to current discussion regarding service experience in professional business services, and 'zooms in' to the context and its detailed layers. It is important to notice that all the three key layers are directly and indirectly influencing each other and are thus inter-related and in continuous interaction. The framework implies the possible challenges that the subjective nature of experience can bring to studying value creation in a dyad - or in a wider ecosystem for that matter and indicates that individuals form an essential contextual layer, which needs to be thoroughly understood also in a B2B dyadic setting. Also, what is regarded as an actor needs to be well defined, when the framework will be implemented in the future empirical research regarding service experience in professional business service relationships.

\section{[Insert here Table 1. Contextual layers of service experience in professional business services]}

\section{Theoretical contribution}

Our research contributes to existing business service research in multiple ways. It acknowledges individual's central role in understanding what is going in the professional business relationships and adds to the current research by taking a look at it from the new and original perspective, namely service experience. Our conceptual framework forms a starting point for further empirical analysis where interlinkages and dynamics between these different layers can be explored in detail. Understanding the roles and interactions between these contextual layers enables us to better understand also dyadic relationships, how they are influencing, and are being influenced by, the surrounding environment. The specific industry of professional services creates a fruitful starting point because of its specific characteristics defined earlier. 
We also suggest that in order to better understand service experience also empirically (i.e. what does it mean and what is important in it when we explore actual business relationships) exploring dyadic relationships is a good starting point, instead of more abstract (and we argue, less concrete) viewpoints onto context.

Based on this study it can be argued that when it comes to the current theoretical understanding, the phenomenon of service experience in professional business relationships is a very complex and ambiguous in nature. It has been investigated from several viewpoints and contextual layers, and with the help of different types of theoretical standpoints. We argue that this may be one of the reasons why the concepts, propositions, premises and definitions regarding service experience, value, and cocreation are still quite diversified, or even vague, and hence quite difficult to comprehend, and why the relationships between different concepts are not always clear. Hence, it is rather challenging to describe and understand service experience thoroughly, let alone to study it empirically. Therefore, comprehensive framework such as the one proposed in this study could be useful for further empirical investigations. We dare to suggest that instead of bringing more and more abstract concepts to the existing discussion, there is need to also empirically try to make sense of this highly important phenomenon in variety of operating contexts.

\section{Managerial implications}

The present paper suggests several managerial implications. With the help of our findings it is easier to analyze service experience formation in professional B-to-B relationships. Our findings (table 1) offer clear guidelines to analyze service experience formation from different angles, even in single company or in some defined dyadic relationship. However, in this it is crucial to understand that professional services represent a versatile industry with different types of services and relationships. 
Certainly, in advertising agencies issues influencing service experience can be very different from service relationships focusing on engineering (Nätti et al., 2016) based on the nature of knowledge used in service provision, or institutional traditions in the industry, for example. So, in managerial applications constant context sensitivity is needed, even within field of B-to-B professional services.

In addition, due to the abstract nature of professional services, it is important for managers to notice that processual characteristics of the relationship and service provision might be as important or even more important than the final outcome of service provision itself. For example, meaning of close relationships and trust between individual professional and his client is a remarkable component in professional service experience, i.e., relationships tend to be highly individual-bound in this context. This creates both positive and negative aspects for managers of professional business service firms to deal with; e.g. how to encourage these kinds of relationships to be formed and further maintained with the key customers so that they could even compensate possible shortcomings in the service outcomes?

On the other hand, tackling risks related to this individual-boundness brings forth more managerial questions; how to balance issues like replacement or distribution of professional work, not to mention professionals tendency to "own" and take control over their customers (Nätti and Ojasalo, 2008b; Jensen et al. 2010)? These are important aspects influencing service experience. However, if these dilemmas are not considered properly, those can even hamper efforts of collective, organizational customer coordination and customer knowledge management (Nätti and Palo, 2012). Consequently, one more critical managerial question in this context is; how to make sense collectively in the customer relationships in this kind of highly individualistic and professional-bound environment to co-create excellent service with the customer? 


\section{Future research avenues}

We also suggest future research avenues. Fundamentally, all these suggestions relate to wider question of moving between micro and macro levels of analysis, and related dilemmas known in social science literature (e.g., Sawyer, 2001; Coleman, 1984; Emirbayer and Mische, 1998): What kind of an influence individual's experience has in organizational setting, related to other individual actors, and what kind of influence different institutional settings can have at different levels of analysis. Therefore, further exploring the role of individual's service experience as a part of a) a dyadic relationship between two individuals, b) professional business service organization's service experience and c) institutional environment would be well-argued in future studies. This can include exploring questions like "How does the service experience of an individual influence the experiences of the other party (individual) in a dyadic professional business relationship, and vice versa?", "How does the service experience of an individual influence the experience of his/her organizational group or even the whole organization?", “How to interpret the organization's service experience?” or "How does institutional environment influence individual's service experience?". We suggest that exploring these questions empirically and in different operating contexts could shed light on the under-studied relationship between individual and collective service experience, and thus create more comprehensive understanding of the service experience and related value. 


\section{References}

Aarikka-Stenroos, L., Sandberg, B. and Lehtimäki, T. (2014), ’Networks for the commercialization of innovations: A review of how divergent network actors contribute", Industrial Marketing Management, Vol. 43 No. 3, pp. 365-381.

Aarikka-Stenroos, L. and Jaakkola, E. (2012), "Value co-creation in knowledge intensive business services: A dyadic perspective on the joint problem solving process", Industrial Marketing Management, Vol. 41 No. 1, pp. 15-26.

Akaka, M., Vargo, S. and Schau, H. (2015), “The context of experience", Journal of Service Management, Vol. 26 No. 2, pp. 206-223.

Akaka, M., and Vargo, S. (2015), "Extending the context of service: from encounters to ecosystems", Journal of Services Marketing, Vol. 29 No. 6/7, pp. 453-462.

Alajoutsijärvi, K., Möller, K. and Rosenbröijer, C-J. (1999), "Relevance of focal nets in understanding the dynamics of business relationships", Journal of Business-to-Business Marketing, Vol. 6 No. 3, pp. 3-35.

Baumeister, R. F. and Leary, M. R. (1997), “Writing narrative literature reviews”, Review of General Psychology, Vol. 1 No. 3, pp. 311-320. 
Bettencourt, L.A., Ostrom, A.L., Brown, S.W. and Roundtree, R. J. (2002), “Client co-production in knowledge-intensive business services”, California Management Review, Vol. 44 No. 4, pp. 100128.

Binkhorst, E. and Den Dekker, T. (2009), “Agenda for Co-Creation Tourism Experience Research”, Journal of Hospitality Marketing and Management, Vol. 18 No. 2-3, pp. 311-327.

Bolton, R.N., Lemon, K.N., Bramlett, M.D. (2006), "The effect of service experiences over time on a supplier's retention of business customers", Management Science, Vol. 52 No. 12, pp. 1811-1823.

Carù, A. and Cova, B. (2015), "Co-creating the collective service experience", Journal of Service Management, Vol. 26 No. 2, pp. 276-294.

Chandler, J. and Vargo, S. (2011), “Contextualization and value-in-context: How context frames exchange", Marketing Theory, Vol. 11 No. 1, pp. 35-49.

Coleman, J. S. (1984), "Introducing social structure into economic analysis", Psychological and Sociological Foundations, Vol. 74 No. 2, pp. 84-88.

Dube, A. and Helkkula, A. (2015), "Service experiences beyond the direct use: indirect customer use experiences of smartphone apps", Journal of Service Management, Vol. 26 No. 2, pp.224-248.

Echeverri, P. and Skålen, P. (2011), “Co-creation and co-destruction: A practice-theory based study of interactive value formation", Marketing Theory, Vol. 11 No. 3, pp. 351-373. 
Edvardsson B, Enquist B and Johnston R (2005), ”Cocreating customer value through hyperreality in the prepurchase service experience”, Journal of Service Research, Vol. 8 No. 2, pp. 149-161.

Edvardsson, B., Tronvoll, B. and Gruber, T. (2011), "Expanding understanding of service exchange and value co-creation: a social construction approach", Journal of the Academy of Marketing Science, Vol. 39 No. 2, pp 327-339.

Edvardsson, B., Kleinaltenkamp, M., Tronvoll, B., McHugh, P. and Windahl, C. (2014), "Institutional logics matter when coordinating resource integration", Marketing Theory, Vol. 14, No. 3, pp. 291309.

Ekman, P., Raggio, R. and Thompson, S. (2016), "Service network value co-creation: Defining the roles of the generic actor", Industrial Marketing Management, Vol. 56, pp. 51-62

Emirbayer, M. and Mische, A. (1998), “What is Agency?”, American Journal of Sociology, Vol. 103 No. 4, pp. 962-1023.

Empson, L. (2001), "Fear of exploitation and fear of contamination: Impediments to knowledge transfer in mergers between professional service firms", Human Relations, Vol. 54 No. 7, pp. 839862.

FitzPatrick, M., Varey, R.J., Grönroos, C., Davey, J. (2015), "Relationality in the service logic of value creation", Journal of Services Marketing, Vol. 29 No. 6/7, pp. 463-471 
Flint, D., Blocker, C. and Boutin, P. (2011), “Customer value anticipation, customer satisfaction and loyalty: An empirical examination”, Industrial Marketing Management, Vol. 40 No. 2, pp. 219-230.

Frow, P. and Payne, A. (2007), “Towards the 'perfect' customer experience", Journal of Brand Management, Vol. 15, pp. 89-101.

Frow, P., McColl-Kennedy, J. and Payne, A. (2016), "Co-creation practices: Their role in shaping a health care ecosystem", Industrial Marketing Management, In press.

Giddens, A. (1984), The constitution of society, Berkeley: University of California Press.

Grewal, D., Levy, M. and Kumar, V. (2009), "Customer experience management in retailing: An organizing framework", Journal of Retailing, Vol. 85 No. 1, pp. 1-14.

Grönroos, C. and Gummerus, J. (2014), “The service revolution and its marketing implications: service logic vs service-dominant logic”, Managing Service Quality: An International Journal, Vol. 24 No. 3, pp. 206-229.

Halinen, A. (1996), "Service quality in professional business services: a relationship approach", in Swartz, T.A., Bowen, D.E. and Brown, S.W. (Eds), Advances in Services Marketing and Management, 5, JAI Press, Greenwich, CT, pp. 315-41.

Heinonen, K. and Strandvik, T. (2015), “Customer-dominant logic: foundations and implications”, Journal of Services Marketing, Vol. 29 No. 6/7, pp. 472-484. 
Helkkula A (2011), "Characterising the concept of service experience", Journal of Service Management, Vol. 22 No. 3, pp. 367-389.

Helkkula, A. and Kelleher, C. (2010), "Circularity of customer service experience and customer perceived value", Journal of Customer Behaviour, Vol. 9 No. 1, pp. 37-53.

Helkkula, A., Kelleher, C. and Pihlström, M. (2012a), "Characterizing value as an experience: implications for service researchers and managers", Journal of Service Research, Vol. 15 No. 1, pp. $59-57$.

Helkkula, A., Kelleher, C. and Pihström, M. (2012b), "Practices and experiences: challenges and opportunities for value research", Journal of Service Management, Vol. 23 No. 4, pp. 554-570.

Helkkula, A., Russo Spena, T., Mele, C., Improta, V. and Kelleher, C. (2015), "Service culture and value experiences of everyday service: North-South divide", Proceedings of the RESER 2015 conference, Copenhangen, Denmark 10. -11.9.2015.

Hill, R. and Johnson, L. W. (2004), "Understanding creative service: A qualitative study of the advertising problem and delineation, communication and response (APDCR) process," International Journal of Advertising, Vol. 23, pp. 285-307.

Holbrook, MB. and Hirschman, EC. (1982a), "Hedonic consumption: emerging concepts, methods and propositions", Journal of Marketing, Vol. 46 No. 3, pp. 92-101. 
Håkansson, H. and Snehota, I. (1989), "No business is an island: The network concept of business strategy”, Scandinavian Journal of Management, Vol. 5 No. 3, pp. 187-200.

Jaakkola, E. and Halinen, A. (2006), "Problem solving within professional services: evidence from the medical field", International Journal of Service Industry Management, Vol. 17 No. 5, pp.409429.

Jaakkola, E., Helkkula, A. and Aarikka-Stenroos, L. (2015a), "Service experience co-creation: conceptualization, implications, and future research directions", Journal of Service Management, Vol. 26 No. 2, pp. 182-205.

Jensen, S. H., Flemming, P. and Kraus, S. (2010), "Managerial routines in professional service firms: transforming knowledge into competitive advantages", The Service Industries Journal, Vol. 30 No. 1, pp. $2045-2062$.

Kennedy, M. M. (2007), “Defining the literature”, Educational Research, Vol. 36 No. 3, pp. 139-147

Korkman, O., Storbacka, K. and B. Harald (2010), "Practices as markets: Value co-creation in einvoicing”, Australasian Marketing Journal, Vol. 18 No. 4, pp. 236-247.

Lemke, F., Clark, M. and Wilson, H. (2011), "Customer experience quality: an exploration in business and consumer contexts using repertory grid technique", Journal of the Academy of Marketing Science, Vol. 39 No. 6, pp. 846-869. 
Leroy, J., Cova, B. and Salle, R. (2013), "Zooming in VS zooming out on value co-creation: Consequences for BtoB research," Industrial Marketing Management, Vol. 42 No. 7, pp. 1102-1111.

Lipkin, M. (2016), "Customer experience formation in today's service landscape", Journal of Service Management, Vol. 27 No. 5, pp.678-703.

Løwendahl B.R, Revang Ø. And Fosstenlokken S. M. (2001. "Knowledge and Value Creation in Professional Service Firms: A Framework for Analysis”, Human Relations, Vol. 54 No.7, pp. 911931.

MacInnis, DJ. (2011), “A framework for conceptual contributions in marketing”, Journal of Marketing, Vol. 75 No. 4, pp. 136-154.

Medlin, CJ. (2004), “Interaction in business relationships: A time perspective”, Industrial Marketing Management, Vol. 33 No. 3, pp. 185-193.

Mele, C., Pels, J. and Storbacka, K. (2015), “A holistic market conceptualization”, Journal of the Academy of Marketing Science, Vol. 43 No. 1, pp. 100-114.

Meyer, C. and Schwager, A. (2007), "Understanding customer experience", Harvard Business Review, February 2007, pp. 1-11.

Marketing Science Institute (2016), Research Priorities 2016-2018. www.msi.org 
Muller, E. and Doloreux, D. (2009), "What we should know about knowledge-intensive business services", Technology in Society, Vol. 31 No. 1, pp. 64-72.

Möller, K. and Halinen, A. (1999), "Business relationships and networks: Managerial challenge of network era", Industrial Marketing Management, Vol. 28 No. 5, pp. 413-427.

North, D. C. (1990), Institutions, institutional change, and economic performance. Cambridge: Cambridge University Press.

Noy, C. (2008), "Sampling knowledge: The hermeneutics of snowball sampling in qualitative research", International Journal of Social Research Methodology, Vol. 11 No. 4, pp. 327-344.

Nätti, S., Ulkuniemi, P. and Pekkarinen, S. (2017), "Implementing modularization in professional services-The influence of varied knowledge environments", Knowledge and Process Management, Vol. 24, issue 2.

Nätti, S. and Ojasalo, J. (2008), "What prevents effective utilisation of customer knowledge in professional B-to-B services? An empirical study", The Service Industries Journal, Vol. 28 No. 9.

Nätti, S. and Palo, T. (2012), ’Key account management in business-to-business expert organisations: an exploratory study on the implementation process", The Service Industries Journal, Vol. 32 No. 11, pp. $1837-1852$.

Ojasalo J. (2001). “Managing Customer Expectations in Professional Services”, Managing Service Quality, Vol. 11 No. 3, pp. 200-212. 
Orlikowski, W. (2007), "Sociomaterial practices: Exploring technology at work", Organization Studies, Vol. 28 No. 9, pp. 1435-1448.

Payne, A., Storbacka, K and Frow, P. (2008), "Managing the co-creation of value", Journal of the Academy of Marketing Science, Vol. 36 No. 1, pp. 83-96.

Ponsignon, F., Klaus, P. and Maull, R. (2015), "Experience co-creation in financial services: an empirical exploration", Journal of Service Management, Vol. 26 No. 2, pp. 295-320.

Prahaland, C.K. and Ramaswamy V. (2004), “Co-creation experiences: The next practice of in value creation", Journal of Interactive Marketing, Vol. 18 No. 3, pp. 5-14.

Ritter, T., Wilkinson, I. and Johnston, W. (2004), "Managing in complex business networks", Industrial Marketing Management, Vol. 33 No. 3, pp. 175-183.

Sawyer, R. K. (2001), "Emergence in Sociology; Contemporary philosophy of mind and some implications for sociological theory”, American Journal of Sociology, Vol. 107 No. 3 pp. 551-585.

Scott, W. R. (2001), Institutions and organizations, Thousand Oaks: Sage.

Smith, D. W. (2007), Husserl, Routledge London. 
Storbacka, K., Brodie, R.J., Böhmann, T., Maglio, P.P., Nenonen, S. (2016), “Actor engagement as a microfoundation for value co-creation", Journal of Business Research, Vol. 69 No. 8, pp. 30083017.

Ulkuniemi. P. \& Nätti, S. (2017), "Personification of experts in professional service relationships", proceedings of $22^{\text {nd }}$ CBIM Academic Workshop in Stockholm School of Economics $19^{\text {th }}-21^{\text {st }}$ If June in 2017.

Vargo, S. and Lusch, R. (2004), "Evolving to a new dominant logic for marketing", Journal of Marketing, Vol. 68, pp. 1-17.

Vargo, S. and Lusch, R. (2008), "Service-dominant logic: continuing the evolution", Journal of the Academy of Marketing Science, Vol. 36 No. 1, pp. 1-10.

Vargo, S. and Lusch, R. (2011), "It's all B2B... and beyond: Toward a systems perspective of the market”, Industrial Marketing Management, Vol. 40 No. 2, pp. 181-18.

Vargo S and Lusch R (2016), "Institutions and axioms: an extension and update of service-dominant logic", Journal of the Academy of Marketing Science, Vol. 44 No 1, pp. 1-19.

Vargo, S., Maglio, P. and Akaka, M. (2008), “On value and value co-creation: A service systems and service logic perspective", European Management Journal, Vol. 26 No. 3, pp. 145-152. 
Verhoef, P.C., Lemon, K.N., Parasuraman, A., Roggeveen, A, Tsiros, M. and Schlesinger, L.A. (2009), "Customer experience creation: Determinants, dynamics and management strategies", Journal of retailing, Vol. 85 No. 1, pp. 31-41.

Von Nordenflycht, A. (2010), "What is a professional service firm? Toward a theory and taxonomy of knowledge-intensive firms", Academy of Management Review, Vol. 35 No. 1, pp. 155-174.

Wenger, E. and Snyder, W. M. (2000), "Communities of Practice: The organizational frontier", Harvard Business Review, January-February 2000.

Wieland, H., Koskela-Huotari, K. and Vargo, S. (2016), "Extending actor participation in value creation: an institutional view", Journal of Strategic Marketing, Vol. 24 No. 3-4, pp. 210-226, 